\title{
Optimal cut-points of different anthropometric indices and their joint effect in prediction of type 2 diabetes: results of a cohort study
}

\author{
Neda Zafari ${ }^{1}$, Mojtaba Lotfaliany ${ }^{1,2}$, Mohammad Ali Mansournia ${ }^{3}$, Davood Khalilii, Fereidoun Azizi ${ }^{1}$
} and Farzad Hadaegh ${ }^{1 *}$

\begin{abstract}
Background: To determine the anthropometric indices that would predict type 2 diabetes (T2D) and delineate their optimal cut-points.

Methods: In a cohort study, 7017 Iranian adults, aged 20-60 years, free of T2D at baseline were investigated. Using Cox proportional hazard models, hazard ratios (HRs) for incident T2D per 1 SD change in body mass index (BMI), waist circumference (WC), waist to height ratio (WHtR), waist to hip ratio (WHR), and hip circumference (HC) were calculated. The area under the receiver operating characteristics (ROC) curves (AUC) was calculated to compare the discriminative power of anthropometric variables for incident T2D. Cut-points of each index were estimated by the maximum value of Youden's index and fixing the sensitivity at 75\%. Using the derived cut-points, joint effects of BMI and other obesity indices on T2D hazard were assessed.
\end{abstract}

Results: During a median follow-up of 12 years, 354 men, and 490 women developed T2D. In both sexes, 1 SD increase in anthropometric variables showed significant association with incident T2D, except for HC in multivariate adjusted model in men. In both sexes, WHtR had the highest discriminatory power while HC had the lowest. The derived cut-points for BMI, WC, WHtR, WHR, and HC were $25.56 \mathrm{~kg} / \mathrm{m}^{2}, 89 \mathrm{~cm}, 0.52,0.91$, and $96 \mathrm{~cm}$ in men and $27.12 \mathrm{~kg} / \mathrm{m}^{2}$, $87 \mathrm{~cm}, 0.56,0.83$, and $103 \mathrm{~cm}$ in women, respectively. Assessing joint effects of BMl and each of the obesity measures in the prediction of incident T2D showed that among both sexes, combined high values of obesity indices increase the specificity for the price of reduced sensitivity and positive predictive value.

Conclusions: Our derived cut-points differ between both sexes and are different from other ethnicities.

Keywords: BMI, Waist circumference, Waist to height ratio, Obesity, Cohort study, Joint effect

\section{Background}

Diabetes is the most prevalent metabolic disorder in the world [1]. It is a coronary heart disease equivalent [2-4] and had a substantial global burden with 680 disability-adjusted life years per 100,000 people in 2010 [1]. By 2035 the prevalence of type 2 diabetes (T2D) will increase by $55 \%$ worldwide with an alarming pace in

\footnotetext{
* Correspondence: fzhadaegh@endocrine.ac.ir

${ }^{1}$ Prevention of Metabolic Disorders Research Center, Research Institute for Endocrine Sciences, Shahid Beheshti University of Medical Sciences, Tehran, Iran

Full list of author information is available at the end of the article
}

developing countries such as those in the Middle East and North Africa region (approximately $96.2 \%$ increase in prevalence in 20 years) [5].

One of the major modifiable risk factors of T2D is obesity [6-10]. Despite clear evidence linking obesity to various health outcomes including cardiovascular diseases (CVD), obesity has been a puzzling condition for clinicians because it is quite heterogeneous [11] and the existing evidence regarding the suitable anthropometric index to be used as a screening test in each sex is controversial. On the one hand, the literature supports the application of central obesity, such as waist to height

(c) The Author(s). 2018 Open Access This article is distributed under the terms of the Creative Commons Attribution 4.0 International License (http://creativecommons.org/licenses/by/4.0/), which permits unrestricted use, distribution, and reproduction in any medium, provided you give appropriate credit to the original author(s) and the source, provide a link to the Creative Commons license, and indicate if changes were made. The Creative Commons Public Domain Dedication waiver (http://creativecommons.org/publicdomain/zero/1.0/) applies to the data made available in this article, unless otherwise stated. 
ratio (WHtR) over general obesity indicators in assessing T2D risk [12, 13]. On the other hand, there are studies that use body mass index (BMI) as their main obesity index in predicting T2D [14-16]. Several studies have been conducted to obtain the optimum cut-points of anthropometric indices [17-22]. However, these studies were mainly conducted in Asians, European and American Caucasians. Understandably, the results are not necessarily generalizable to other ethnicities [23]. Therefore, WHO has emphasized the need for prospective studies to derive and validate ethnic-specific cut-points of body fat composition indices to predict CVD and T2D [24].

Located in the Middle East, Iran suffers from high incidence and prevalence of T2D $[10,25]$. Yet, data regarding appropriate anthropometric cut-points in the Iranian population using prospective studies is limited [26].

In the current study, we decided to determine the sex-specific independent and combined risk of different anthropometric indices in the prediction of T2D in the cohort of Tehran Lipid and Glucose Study (TLGS) with over 12 years of follow-up; furthermore, we compared the discriminatory power of adiposity measures and delineated their optimal cut-points in this population.

\section{Methods}

\section{Study design and sample}

The TLGS, an ongoing prospective population-based study being performed on a representative sample of the Tehran population, aims to determine the prevalence and incidence of non-communicable diseases and their risk factors. Detailed descriptions of the TLGS have been reported elsewhere [27]. In brief, one baseline (1999-2001) and 4 follow-up examinations at triennial intervals have been carried out until January 2015. Those who had cancer, end-stage renal disease or cirrhosis were excluded from the TLGS at the baseline examination [28]. For the current study, 10,727 participants, aged 20-60 years [8569 people from the baseline examination (1999-2001) and 2158 new participants recruited from the second phase (2001-2005)], were selected. Subjects with prevalent T2D at their baseline examination $[N=806$, excluding those with known T2D using anti-diabetic medications $(N=276), 32$ participants had isolated high fasting plasma glucose (FPG), 95 subjects had high FPG levels while their 2 h-post-challenge plasma glucose (2 h-PCPG) was missing, 202 participants had isolated high $2 \mathrm{~h}$-PCPG and 201 had combined high FPG and high 2 h-PCPG], no data on baseline variables $(N=1342)$ or not any follow-up data $(N=1562)$ were excluded; leaving 7017 participants (2988 men, 4029 women) to include in the analyses as respondents (response rate $=7017 /(10,727-806) \times 100=70.7 \%)$. Furthermore, to compare the discriminatory power of anthropometric indices and to delineate their optimal cut-points for the prediction of T2D in each sex, the analyses were performed only among those who participated in the last follow-up phase and those with incident T2D during the follow-ups ( $N=5738,2419$ men, 3319 women) (Additional file 1).

\section{Clinical and laboratory measurements}

Using a pretested questionnaire, a trained interviewer collected information regarding demographic data, drug history and family history of T2D. Weight was measured, with subjects minimally clothed without shoes, using digital scales (Seca 707: range 0-150 kg) and recorded to the nearest $1 \mathrm{~kg}$. Using a tape meter, height was measured in a standing position without shoes, while shoulders were in normal alignment; waist circumference (WC) was measured at the umbilical level and that of the hip $(\mathrm{HC})$ at the widest girth of the hip over light clothing, without any pressure to the body surface. Measurements were recorded to the nearest $1 \mathrm{~cm}$. Body mass index (BMI) was calculated as weight $(\mathrm{Kg})$ divided by height squared $\left(\mathrm{m}^{2}\right)$. Waist to hip (WHR) and waist to height ratios (WHtR) were calculated as WC $(\mathrm{cm})$ divided by $\mathrm{HC}(\mathrm{cm})$ and height $(\mathrm{cm})$, respectively. Wrist circumference was measured with the anterior wrist surface facing up. The superior border of the tape meter was placed just distal to the prominences of the radial and ulnar bones, without any tape pressure over it; values were recorded to the nearest $0.1 \mathrm{~cm}$.

After a 15-min rest in the sitting position, two measurements of systolic and diastolic blood pressure (SBP and DBP) were taken on the right arm, using a standardized mercury sphygmomanometer (calibrated by the Iranian Institute of Standards and Industrial Researches); the mean of the two measurements was considered as the participant's blood pressure.

A blood sample was taken between 7:00 and 9:00 AM from all study participants, after 12 to $14 \mathrm{~h}$ of overnight fasting. All blood analyses were carried out at the TLGS research laboratory on the day of the blood collection. For all non-pharmacologically treated diabetic participants aged $\geq 20$ years, an oral glucose tolerance test with $82.5 \mathrm{~g}$ of glucose monohydrate solution [equivalent to $75 \mathrm{~g}$ of anhydrous glucose; Cerestar EP, Spain] was performed; a second blood sample was obtained $2 \mathrm{~h}$ after glucose ingestion. Fasting plasma glucose (FPG) and $2 \mathrm{~h}$-post-challenge plasma glucose ( $2 \mathrm{~h}$-PCPG) were measured using an enzymatic colorimetric method with glucose oxidase; inter- and intra-assay coefficients of variation at baseline and follow-up phases were both less than $2.3 \%$.

High-density lipoprotein cholesterol (HDL-C) was measured after precipitation of the apolipoprotein $\mathrm{B}$ containing lipoproteins with phosphotungstic acid. Triglycerides (TG) were assayed using glycerol phosphate 
oxidase. Both inter- and intra-assay coefficients of variation were less than 3 and $2.1 \%$ for HDL-C and TG, respectively. Analyses were performed using Pars Azmon kits (Pars Azmon Inc., Tehran, Iran) and a Selectra 2 auto-analyzer (Vital Scientific, Spankeren, Netherlands). Triglyceride to high-density lipoprotein cholesterol ratio (TG/HDL-C) was calculated by dividing TG to HDL-C. All samples were analyzed when internal quality control met the acceptance criteria.

\section{Definition of terms}

Subjects who reported a parent or sibling with diabetes were considered as having a positive family history of T2D. Education level was classified in 3 categories: i) those who had studied less than 6 years, ii) those who had studied for 6-12 years, and iii) those with more than 12 years of education. In accordance with the definition provided by the American Diabetes Association, [29] participants were considered to have T2D if they met at least one of these criteria: FPG $\geq 7.0 \mathrm{mmol} / \mathrm{L}$, or $2 \mathrm{~h}-\mathrm{PCPG} \geq 11.1 \mathrm{mmol} / \mathrm{L}$ or taking anti-diabetic medication. In addition, participants with missing data on 2 h-PCPG at follow-up who simultaneously had FPG levels $<5.05 \mathrm{mmol} / \mathrm{L}$ were considered free of T2D [30].

\section{Statistical methods}

All statistical analyses were stratified by sex. Continuous variables were described as mean (standard deviation (SD)) or median (interquartile range (IQR)), and categorical variables were summarized as frequency (percentage). Baseline characteristics of men and women, as well as respondent and non-respondent groups, were compared using independent T-test, Mann-Whitney U test, and Chi-square test whichever indicated. The event date for diabetes cases was described as the middle-time between the date of follow-up visit at which diabetes was detected for the first time, and the most recent follow-up visit preceding the diagnosis; the follow-up time was considered as the difference between the calculated mid-time date and the date at which the subjects entered the study. For the censored subjects, the survival time was the interval between their first and last observation dates.

Cox proportional hazard models with age as the time scale [31] were used to estimate the hazard ratios (HRs) with 95\% confidence intervals (95\% CIs) for incident T2D per 1 SD increase in anthropometric indices in univariate (without adjustment for any other variables) and adjusted multivariable models. In model 1, the hazard ratio of interest was adjusted for education, family history of T2D, SBP, FPG, and TG/HDL-C. In model 2, the hazard ratio of interest was adjusted for variables included in model 1 plus wrist circumference as it has been shown to be a significant predictor of T2D in the TLGS adult population [32].

The proportional hazards assumption in the Cox models was assessed both graphically and using the Schoenfeld residual test. All proportionality assumptions were met. Collinearity was checked by estimating the first order correlation coefficients between variables used in each model as well as using correlation matrix of coefficients in the multivariable adjusted cox model [33]. There was no pair of variables with correlation coefficient of 0.80 or more in models. Receiver operating characteristics (ROC) curves were plotted to compare the discriminative power of different anthropometric indices for the prediction of incident T2D. The equality of the area under the ROC curves (AUCs) of different anthropometric indices was tested using the Stata command 'roccomp' [34]. Using the "R optimal cut-point package", [35] cut-points for each variable were estimated by i) the maximum value of Youden's index i.e., sensitivity+specificity-1, [36] ii) setting the sensitivity at $75 \%$.

To examine the joint effects of BMI-WC, BMI-WHtR, BMI-WHR, and BMI-HC on the hazard of T2D in each sex, combined variables were created. To compare 4 categories, considering those with normal BMI-WC, BMI-WHtR, BMI-WHR, and BMI-HC as reference groups, using our cut-points derived from the fixed sensitivity at $75 \%$, Cox proportional hazard models with age as the time scale were used in univariate and adjusted multivariable models. Model 1 was adjusted for education, family history of T2D, SBP, FPG, and TG/HDL-C. Model 2 was adjusted for variables included in model 1 and wrist circumference. All analyses were done using Stata (version 12.0) and R (version 3.4.3).

\section{Results}

The study population consisted of 2988 men and 4029 women with the mean (SD) ages of 37.8 (10.2) and 37.3 (10.4) years, respectively. Baseline characteristics of respondents and non-respondents (eligible participants whose baseline or follow-up data were missing) are shown in Additional file 2. The only significant difference between these two groups was that respondents were 4 years older than their non-respondent counterparts. All other variables were generally the same in both groups. Table 1 depicts baseline characteristics of respondent men and women. Men were older and had higher levels of education, wrist circumference, SBP, FPG and log TG/HDL-C. Regarding anthropometric indices, men had higher WC and WHR, whereas, BMI, $\mathrm{HC}$, and WHtR were higher in women. Frequency of baseline consumption of angiotensin-converting enzyme inhibitors (ACEIs), diuretics, corticosteroids and lipid-lowering drugs in men were $0.6,0.5,1.5$, and $1.4 \%$, 
Table 1 Baseline characteristics ${ }^{a}$ of respondents, Tehran Lipid and Glucose Study (1999-2015)

\begin{tabular}{llll}
\hline & Men $(\mathrm{N}=2988)$ & Women $(\mathrm{N}=4029)$ & Difference $(\mathrm{Cl})$ \\
\hline Age (years) & $37.8(10.2)$ & $37.3(10.4)$ & $0.5(0.0 ; 0.1)$ \\
Family History of T2D; No. (\%) & $790(26.4)$ & $1115(27.7)$ & $-1.2 \%(-3.3 ; 0.8)$ \\
Education Level; No. (\%) & & & $-12.2 \%(-14.1 ;-10.3)$ \\
$\quad<6$ years & $471(15.8)$ & $1127(28.0)$ & $3.6 \%(1.2 ; 5.9)$ \\
$\quad 6-12$ years & $1888(63.2)$ & $2402(59.6)$ & $8.6 \%(7.8 ; 10.4)$ \\
$\quad>12$ years & $629(21.1)$ & $500(12.4)$ & $1.7(1.6 ; 1.7)$ \\
Wrist Circumference (cm) & $17.6(1.0)$ & $15.9(1.0)$ & $2.4(1.8 ; 2.9)$ \\
WC (cm) & $88.4(11.1)$ & $86.0(12.3)$ & $13.7(13.4 ; 14.0)$ \\
Height (cm) & $171.1(6.6)$ & $157.4(5.8)$ & $-0.03(-0.033 ;-0.026)$ \\
WHtR & $0.51(0.06)$ & $0.54(0.08)$ & $-1.5(-1.7 ;-1.3)$ \\
BMI (kg/m $\left.{ }^{2}\right)$ & $25.7(4.1)$ & $27.2(4.9)$ & $-7.1(-7.6 ;-6.7)$ \\
HC(cm) & $96.8(7.2)$ & $103.9(9.5)$ & $0.08(0.08 ; 0.09)$ \\
WHR & $0.91(0.06)$ & $0.82(0.07)$ & $2.5(1.8 ; 3.3)$ \\
SBP (mmHg) & $116.0(14.1)$ & $113.5(15.6)$ & $0.8(0.3 ; 1.3)$ \\
DBP (mmHg) & $76.6(10.3)$ & $75.8(10.3)$ & $0.09(0.07 ; 1.2)$ \\
FPG (mmol/L) & $5.00(0.50)$ & $4.91(0.51)$ & $0.37(0.34 ; 0.40)$ \\
Log TG/HDL-C & $0.60(0.71)$ & $0.26(0.69)$ & \\
\hline
\end{tabular}

${ }^{a}$ For continuous variables, values are presented as mean (SD) and difference $(95 \% \mathrm{Cl})$ was estimated using linear regression models. Categorical variables are presented as frequency (percentage) and difference $(95 \% \mathrm{Cl})$ was estimated by logistic regression

$C l$ confidence interval, T2D type 2 diabetes mellitus, WC waist circumference, WHtR waist to height ratio, $B M I$ body mass index, $H C$ hip circumference, WHR waist to hip ratio, SBP systolic blood pressure, DBP diastolic blood pressure, FPG fasting plasma glucose, $T G / H D L-C$ triglyceride to high density lipoprotein cholesterol ratio

respectively; the corresponding values for women were $0.7,1.9,1.9$, and $2 \%$, respectively.

During a median follow-up (IQR) of 11.9 (4.6) years, 354 new cases of T2D in men and 490 ones in women were detected resulting in an annual crude incidence rate $(95 \% \mathrm{CI})$ of $10.9(9.8-12.1)$ and 11.1 (10.1-12.1) diabetes per 1000 person-years of follow-up in men and women, respectively. Table 2 illustrates sex-specific adjusted HRs (95\% CIs) for incident T2D per $1 \mathrm{SD}$ increase in anthropometric indices using the univariate and multivariable-adjusted Cox proportional hazard models. In men, in line with the univariate model, model 1 indicated statistically significant associations between all anthropometric measures and T2D incidence with HRs ranging from 1.25 for $\mathrm{HC}$ to 1.37 for BMI. Considering the wrist circumference as a surrogate of body frame in model 2, the hazardous association of all the obesity measures for development of T2D was shown except for HC (HR 0.92, 95\% CI: 0.80-1.06). In women, similar to the univariate model, model 1 indicated statistically significant hazardous associations between all anthropometrics and incident $\mathrm{T} 2 \mathrm{D}$, with HRs ranging from 1.24 for $\mathrm{HC}$ to 1.51 for WHtR. However, after adjusting for wrist circumference in model 2, all the HRs decreased but still remained statistically significant.

Fig. 1 shows sex-specific ROC curves and the AUCs (95\% CIs) for different anthropometric indices. In both sexes, WHtR had the highest AUC (0.69, 95\% CI: $0.67-0.72$, in men and $0.75,95 \% \mathrm{CI}: 0.73-0.78$, in women), whereas $\mathrm{HC}$ had the lowest values $(0.62,95 \%$ CI: $0.59-0.65$, in men and 0.66, 95\% CI: 0.64-0.69, in women).

Table 3 shows the sex-specific cut-points of different anthropometric indices for the prediction of incident T2D. In men, fixing sensitivity at $75 \%$, the calculated cut-points for BMI, WC, WHtR, WHR, and HC were $25.56 \mathrm{~kg} / \mathrm{m}^{2}, 89 \mathrm{~cm}, 0.52,0.91$, and $96 \mathrm{~cm}$ while the corresponding values for the Youden's index were $26.49 \mathrm{~kg} / \mathrm{m}^{2}, 87 \mathrm{~cm}, 0.54,0.92$, and $96 \mathrm{~cm}$, respectively. In women, fixing sensitivity at $75 \%$, the calculated cut-points for BMI, WC, WHtR, WHR, and HC were $27.12 \mathrm{~kg} / \mathrm{m}^{2}, 87 \mathrm{~cm}, 0.56,0.83$, and $103 \mathrm{~cm}$ while the corresponding values for the Youden's index were $29.27 \mathrm{~kg} / \mathrm{m}^{2}, 91 \mathrm{~cm}, 0.56,0.83$, and $106 \mathrm{~cm}$, respectively.

Table 4, illustrates the joint effects of BMI and other obesity measures on the hazard of developing T2D, based on the cut-points derived from the fixed sensitivity at $75 \%$, in men. As shown in the table, high BMI, whether alone or combined with high other obesity measures, had a significant risk for incident T2D both in univariate and multivariate models (except for high BMI-low HC). Among men population with normal BMI, only the presence of high WHR showed significant risk for incident T2D in the fully adjusted analysis (HR 1.55, 95\% CI: $1.01-2.38)$. 
Table 2 Associations between anthropometric indices and incident type 2 diabetes, Tehran Lipid and Glucose Study (1999-2015)

\begin{tabular}{|c|c|c|c|c|c|c|}
\hline & \multicolumn{2}{|l|}{ Univariate model } & \multirow{2}{*}{$\begin{array}{l}\text { Model 1 } \\
\text { HR }(95 \% \text { Cl) }\end{array}$} & \multicolumn{3}{|c|}{ Model $2^{c}$} \\
\hline & $\mathrm{HR}^{\mathrm{a}}(95 \% \mathrm{Cl})$ & $P$-value & & $P$-value & HR (95\% Cl) & $P$-value \\
\hline \multicolumn{7}{|l|}{ Men } \\
\hline BMI $\left(\mathrm{kg} / \mathrm{m}^{2}\right)$ & 1.69 (1.54-1.85) & $<0.001$ & $1.37(1.24-1.51)$ & $<0.001$ & $1.48(1.31-1.68)$ & $<0.001$ \\
\hline WC (cm) & 1.69 (1.52-1.87) & $<0.001$ & $1.35(1.21-1.50)$ & $<0.001$ & $1.43(1.26-1.64)$ & $<0.001$ \\
\hline WHtR & $1.66(1.51-1.83)$ & $<0.001$ & $1.36(1.23-1.50)$ & $<0.001$ & $1.39(1.24-1.55)$ & $<0.001$ \\
\hline WHR & $1.52(1.38-1.67)$ & $<0.001$ & $1.27(1.14-1.41)$ & $<0.001$ & $1.26(1.13-1.40)$ & $<0.001$ \\
\hline $\mathrm{HC}(\mathrm{cm})$ & $1.52(1.38-1.67)$ & $<0.001$ & $1.25(1.14-1.37)$ & $<0.001$ & $0.92(0.80-1.06)$ & 0.304 \\
\hline \multicolumn{7}{|l|}{ Women } \\
\hline BMI $\left(\mathrm{kg} / \mathrm{m}^{2}\right)$ & $1.74(1.60-1.89)$ & $<0.001$ & $1.42(1.30-1.56)$ & $<0.001$ & $1.41(1.27-1.57)$ & $<0.001$ \\
\hline WC (cm) & $1.90(1.74-2.08)$ & $<0.001$ & $1.48(1.34-1.64)$ & $<0.001$ & $1.46(1.30-1.64)$ & $<0.001$ \\
\hline WHtR & $1.93(1.76-2.12)$ & $<0.001$ & $1.51(1.37-1.68)$ & $<0.001$ & $1.47(1.32-1.64)$ & $<0.001$ \\
\hline WHR & $1.57(1.44-1.71)$ & $<0.001$ & $1.30(1.19-1.42)$ & $<0.001$ & $1.27(1.16-1.39)$ & $<0.001$ \\
\hline $\mathrm{HC}(\mathrm{cm})$ & $1.46(1.35-1.58)$ & $<0.001$ & $1.24(1.14-1.35)$ & $<0.001$ & $1.11(1.00-1.24)$ & 0.043 \\
\hline
\end{tabular}

${ }^{\mathrm{a}}$ Per $1 \mathrm{SD}$ increase for each index $(\mathrm{SD}$ of $\mathrm{WC}=11.13, \mathrm{BMI}=4.08, \mathrm{HC}=7.16, \mathrm{WHR}=0.06, \mathrm{WHtR}=0.06$ in men and $\mathrm{WC}=12.31, \mathrm{BMI}=4.90, \mathrm{HC}=9.51, \mathrm{WHR}=0.07$, $\mathrm{WHtR}=0.08$ in women)

${ }^{\mathrm{b}}$ Adjusted for age (in time-scale manner), education level, family history of type 2 diabetes, systolic blood pressure, fasting plasma glucose, and triglyceride to high-density lipoprotein cholesterol ratio

${ }^{c}$ Adjusted for model 1 variables and wrist circumference

$H R$ hazard ratio, $C l$ confidence interval, $B M I$ body mass index, WC waist circumference, WHtR waist to height ratio, WHR waist to hip ratio, HC hip circumference

Table 5, illustrates the joint effects of BMI and other obesity measures on the hazard of incident T2D, based on the derived cut-points from the fixed sensitivity at $75 \%$, in women. Analyses revealed that high obesity measures whether alone or in combination with each other were generally associated with higher risk of developing T2D compared to the reference group. However, there were two exceptions: i) in those with high BMI-normal WHtR whose increased risk was not statistically significant in the multivariate models and ii) in those with normal BMI-high $\mathrm{HC}$ whose HRs were not significantly increased neither in univariate nor in multivariate models.

Table 6 depicts the sensitivity, specificity and positive predictive value (PPV) of combinations of high BMIhigh WC, high BMI- high WHtR, high BMI- high WHR, and high BMI- high $\mathrm{HC}$ using the derived cut-points by fixing sensitivity at $75 \%$ in men and women. As shown in the table, all the sensitivities fell to values under $70 \%$, whereas the reported specificities were increased compared to the values displayed in Table 3 . The overall effect of combining high measures together was a mild reduction in the PPVs.

\section{Discussion}

Investigated in a large Iranian cohort study with 12 years of follow-up, all anthropometric variables showed significant association with incident T2D after adjustment for a wide set of covariates including a surrogate of body frame (wrist circumference) in both sexes, excluding hip circumference in men. Assessing their discriminatory power, in both sexes, WHtR performed the best, whereas $\mathrm{HC}$ showed the lowest prediction power. The derived cut-points of anthropometric indices for predicting the development of T2D in our population were generally different for men and women. Investigating the accuracy of combination of BMI and other obesity measures in predicting development of T2D revealed that in both sexes, the combined high values of general and central obesity indices increase the specificity for the price of reduced sensitivity and PPV.

In literature, there is almost unanimous agreement on the association of all general and central obesity measures with incident T2D in both sexes [15, 17, 19, 20, 22, 37-39]. However, controversy remains as to which index can predict incident T2D, independent of other obesity variables. While several studies suggest central obesity measures as the main obesity indices predicting T2D in men, [38-40]. there are investigations highlighting the role of general obesity as the optimal index $[14,15]$. In line with other studies, we found that in both men and women, all anthropometric indices are almost similarly associated with T2D. Moreover, in our study, while wrist circumference acted as a positive risk factor for developing T2D in women, in men it showed a negative association. Similarly, Jahangiri et al. showed the positive association between wrist circumference and incident T2D in women [32].

With regards to $\mathrm{HC}$, similar to other studies, [41-43] we showed the hazardous association of larger $\mathrm{HC}$ with development of T2D in both sexes in the multivariate analysis adjusted for traditional T2D risk factors; the 

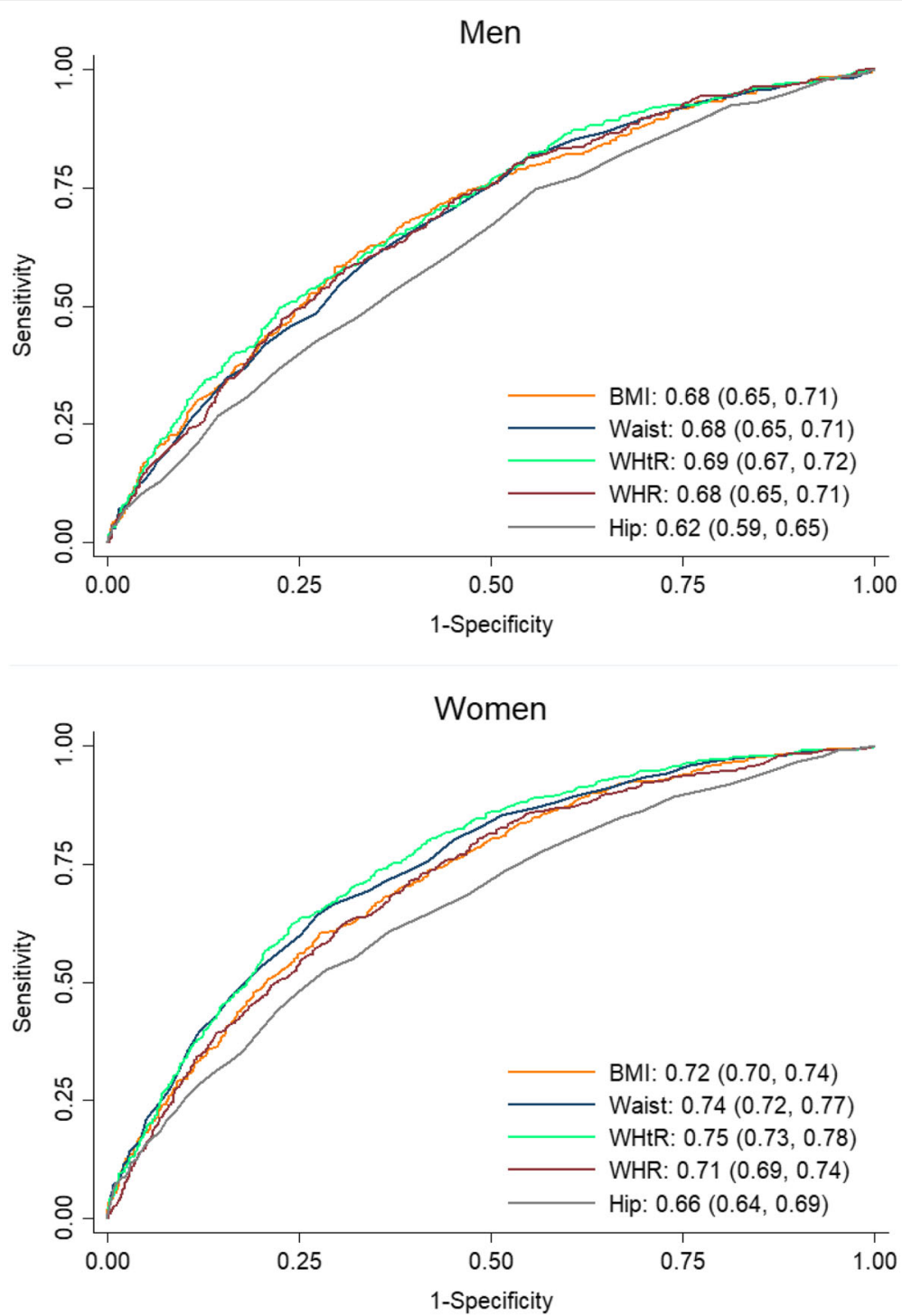

Fig. 1 Receiver operating characteristic (ROC) curves, area under the curves (AUCs) and 95\% confidence intervals for different anthropometrics by gender. P-values for AUCs comparison in men: BMI-WC: 0.51; BMI-WHR: 0.84; BMI-WHtR: 0.11; BMI-HC: <0.001; WC-WHR: 0.80; WC-WHtR: 0.002; WC-HC: $<0.001$; WHtR-HC: <0.001; WHR-WHtR: 0.10; WHR-HC: <0.001. P-values for AUCs comparison in women: BMI-WC: 0.002; BMI-WHR: 0.68; BMI-WHtR: <0.001; BMI-HC: <0.001; WC-WHR: 0.001; WC-WHtR: 0.004; WC-HC: <0.001; WHtR-HC: <0.001; WHR-WHtR: <0.001; WHR-HC: 0.003. WHtR, waist to height ratio; WC, waist circumference; WHR, waist to hip ratio; BMI, body mass index

association which reached to null after considering body frame (wrist circumference) in men. Moreover, further adjustment of $\mathrm{HC}$ for BMI, as suggested by many investigators, $[44,45]$ reversed this association only in women (HR 0.77, 95\% CI: 0.65-0.92 in women, HR 0.82 95\% C: $0.66-1.02$ in men). Obesity is linked to higher risk of T2D [46]. However, there are studies which has reported a better metabolic profile in individuals who had more gluteofemoral mass for a given amount of abdominal fat [47-49]. The possible explanation for such effect is that $\mathrm{HC}$ is a presentation of several components namely the bone, the gluteal muscles, and the gluteal subcutaneous fat [50]. Each component plays its own role in the process of developing T2D. Gluteal muscles are one of the main sites of insulin receptors. Therefore, higher gluteal muscle mass may be indicative reduced risk of insulin resistance which is commonly followed by development of T2D. The effect of gluteofemoral fat mass on metabolism has been investigated in physiological studies [51, 52]. A study by Manolopoulos et al [52] proposed that the fat mass in the gluteofemoral region traps the surfeit serum fatty acids which results in a low serum lipid levels. Furthermore, authors suggested that secreting adipokines leptin and adiponectin, the gluteofemoral fat mass might play a protective role in the development of T2D. Finally, Kuk et al. showed that in 
Table 3 Sex-specific diagnostic test performance of the anthropometric indices for incident type 2 diabetes, TLGS study

\begin{tabular}{|c|c|c|c|c|c|c|}
\hline & Cut-point & No. of subjects above cut-point & No. of Incident T2D & Sensitivity (\%) & Specificity (\%) & PPV (\%) \\
\hline \multicolumn{7}{|l|}{ Men $(N=2419)$} \\
\hline \multicolumn{7}{|l|}{$\mathrm{BMI}\left(\mathrm{kg} / \mathrm{m}^{2}\right)$} \\
\hline Youden's index & 26.49 & 1043 & 243 & 67.7 & 61.4 & 23.3 \\
\hline Sensitivity $=75 \%$ & 25.56 & 1258 & 269 & 74.9 & 52.0 & 21.4 \\
\hline \multicolumn{7}{|l|}{ WC $(\mathrm{cm})$} \\
\hline Youden's index & 87.00 & 1415 & 292 & 81.3 & 45.5 & 20.6 \\
\hline Sensitivity $=75 \%$ & 89.00 & 1254 & 265 & 73.8 & 52.0 & 21.1 \\
\hline \multicolumn{7}{|l|}{$\mathrm{WH}+\mathrm{R}$} \\
\hline Youden's index & 0.54 & 940 & 224 & 62.7 & 65.0 & 23.8 \\
\hline Sensitivity $=75 \%$ & 0.52 & 1229 & 262 & 74.9 & 51.4 & 21.3 \\
\hline \multicolumn{7}{|l|}{ WHR } \\
\hline Youden's index & 0.92 & 1122 & 246 & 71.9 & 55.5 & 21.9 \\
\hline Sensitivity $=75 \%$ & 0.91 & 1247 & 267 & 75.2 & 50.3 & 21.4 \\
\hline \multicolumn{7}{|l|}{$\mathrm{HC}(\mathrm{cm})$} \\
\hline Youden's index & 96.00 & 1418 & 268 & 74.6 & 44.2 & 18.9 \\
\hline Sensitivity $=75 \%$ & 96.00 & 1418 & 268 & 74.6 & 44.2 & 18.9 \\
\hline \multicolumn{7}{|l|}{ Women $(N=3319)$} \\
\hline \multicolumn{7}{|l|}{ BMI $\left(\mathrm{kg} / \mathrm{m}^{2}\right)$} \\
\hline Youden's index & 29.27 & 1080 & 300 & 60.4 & 72.4 & 27.8 \\
\hline Sensitivity $=75 \%$ & 27.12 & 1619 & 373 & 75.0 & 55.8 & 23.0 \\
\hline \multicolumn{7}{|l|}{ WC (cm) } \\
\hline Youden's index & 91.00 & 1166 & 331 & 66.6 & 70.4 & 28.4 \\
\hline Sensitivity $=75 \%$ & 87.00 & 1557 & 376 & 75.6 & 58.2 & 24.1 \\
\hline \multicolumn{7}{|l|}{$\mathrm{WH} t \mathrm{R}$} \\
\hline Youden's index & 0.56 & 1365 & 366 & 73.6 & 64.8 & 26.8 \\
\hline Sensitivity $=75 \%$ & 0.56 & 1414 & 373 & 75.0 & 63.1 & 26.4 \\
\hline \multicolumn{7}{|l|}{ WHR } \\
\hline Youden's index & 0.83 & 1502 & 358 & 73.0 & 59.1 & 23.8 \\
\hline Sensitivity $=75 \%$ & 0.83 & 1589 & 371 & 75.0 & 56.7 & 23.3 \\
\hline \multicolumn{7}{|l|}{$\mathrm{HC}(\mathrm{cm})$} \\
\hline Youden's index & 106.00 & 1338 & 302 & 60.8 & 63.3 & 22.6 \\
\hline Sensitivity $=75 \%$ & 103.00 & 1833 & 367 & 73.8 & 48.0 & 20.0 \\
\hline
\end{tabular}

$T 2 D$ type 2 diabetes mellitus, $P P V$ positive predictive value, $B M I$ body mass index, $W C$ waist circumference, $W H t R$ waist to height ratio, $W H R$ waist to hip ratio, $H C$ hip circumference

both sexes, for a given WC, higher $\mathrm{HC}$ is associated with higher gluteofemoral and abdominal subcutaneous fat mass and skeletal muscle while being associated with lower visceral fat mass [53].

Regarding the discriminatory power of anthropometric measures, in both sexes, among all the investigated anthropometric measures, WHtR had the highest prediction power, whereas $\mathrm{HC}$ had the lowest. Results of the current study are in line with several cohort studies [17, 22]. Previously, in short-term follow-up, we showed the superiority of WHtR to BMI in the prediction of T2D in both genders $[54,55]$. The differences between our short versus long-term follow up studies might be due to different follow-up times, statistical approaches and covariates. Recently, a systematic review and meta-analysis by Ashwell et al [13] revealed a stronger association of WHtR with T2D rather than BMI in both genders.

In the current study, we looked for cut-points of different anthropometric measures using Youden's index, which gives equal weight to both the sensitivity and specificity. Clinically, however, these may not be the appropriate cut-points since sensitivity versus specificity must be weighed against the seriousness of the disease, and the test under evaluation (whether it 
Table 4 Joint-effects of BMI and other central obesity measures on the hazard of type 2 diabetes in men, TLGS study

\begin{tabular}{|c|c|c|c|c|c|c|c|}
\hline & \multirow{2}{*}{$\begin{array}{l}\text { Incident T2D /total participants } \\
\text { (\%) }\end{array}$} & \multicolumn{2}{|l|}{ Univariate model } & \multicolumn{2}{|l|}{ Model $1^{a}$} & \multicolumn{2}{|l|}{ Model $2^{b}$} \\
\hline & & HR $(95 \% \mathrm{Cl})$ & $P$ Value & HR (95\% Cl) & $P$-value & $\mathrm{HR}(95 \% \mathrm{Cl})$ & $P$-value \\
\hline \multicolumn{8}{|c|}{ BMI $\left(\mathrm{kg} / \mathrm{m}^{2}\right)-W C(\mathrm{~cm})$} \\
\hline$<25.56-<89$ & 70/1302 (5.38) & Reference & - & Reference & - & Reference & - \\
\hline$\geq 25.56-<89$ & 24/191 (12.57) & $2.23(1.40-3.56)$ & 0.001 & $1.75(1.10-2.80)$ & 0.018 & $1.83(1.14-2.95)$ & 0.012 \\
\hline$<25.56-\geq 89$ & 19/184 (10.33) & $1.54(0.93-2.57)$ & 0.093 & $1.04(0.62-1.74)$ & 0.879 & $1.07(0.64-1.81)$ & 0.778 \\
\hline$\geq 25.56-\geq 89$ & 241/1311 (18.38) & $3.13(2.39-4.09)$ & $<0.001$ & $2.21(1.67-2.91)$ & $<0.001$ & $2.38(1.75-3.25)$ & $<0.001$ \\
\hline \multicolumn{8}{|l|}{$\mathrm{BMI}\left(\mathrm{kg} / \mathrm{m}^{2}\right)-\mathrm{WHtR}$} \\
\hline$<25.56-<0.52$ & 73/1311 (5.57) & Reference & - & Reference & - & Reference & - \\
\hline$\geq 25.56-<0.52$ & 24/202 (11.88) & $2.09(1.32-3.32)$ & 0.002 & $1.73(1.08-2.75)$ & 0.020 & $1.81(1.13-2.92)$ & 0.014 \\
\hline$<25.56-\geq 0.52$ & 16/175 (9.14) & $1.18(0.68-2.04)$ & 0.549 & $0.80(0.46-1.40)$ & 0.444 & $0.80(0.46-1.39)$ & 0.437 \\
\hline$\geq 25.56-\geq 0.52$ & 241/1300 (18.54) & $2.98(2.28-3.88)$ & $<0.001$ & $2.08(1.58-2.74)$ & $<0.001$ & $2.20(1.64-2.97)$ & $<0.001$ \\
\hline \multicolumn{8}{|l|}{$\mathrm{BMI}\left(\mathrm{kg} / \mathrm{m}^{2}\right)-\mathrm{WHR}$} \\
\hline$<25.56-<0.91$ & 48/1116 (4.3) & Reference & - & Reference & - & Reference & - \\
\hline$\geq 25.56-<0.91$ & $44 / 354(12.43)$ & $2.89(1.92-4.36)$ & $<0.001$ & $2.08(1.37-3.15)$ & 0.001 & $2.20(1.43-3.38)$ & $<0.001$ \\
\hline$<25.56-\geq 0.91$ & $41 / 370(11.08)$ & $2.05(1.34-3.13)$ & 0.001 & $1.54(1.00-2.36)$ & 0.047 & $1.55(1.01-2.38)$ & 0.044 \\
\hline$\geq 25.56-\geq 0.91$ & $221 / 1148(11.85)$ & $3.87(2.82-5.31)$ & $<0.001$ & $2.70(1.95-3.74)$ & $<0.001$ & $2.88(2.03-4.08)$ & $<0.001$ \\
\hline \multicolumn{8}{|l|}{ BMI (kg/m2)- HC } \\
\hline$<25.56-<96$ & 68/1147 (5.93) & Reference & - & Reference & - & Reference & - \\
\hline$\geq 25.56-<96$ & 23/158 (14.56) & 1.98(1.23-3.18) & 0.005 & $1.35(0.83-2.19)$ & 0.224 & $1.41(0.86-2.30)$ & 0.164 \\
\hline$<25.56-\geq 96$ & 21/339 (6.19) & $1.03(0.63-1.69)$ & 0.881 & $0.86(0.52-1.41)$ & 0.564 & $0.92(0.55-1.51)$ & 0.774 \\
\hline$\geq 25.56-\geq 96$ & 242/1344 (18.01) & $2.92(2.23-3.83)$ & $<0.001$ & $2.15(1.63-2.84)$ & $<0.001$ & $2.40(1.75-3.30)$ & $<0.001$ \\
\hline
\end{tabular}

is a simple measurement or an invasive test and its cost). Hence, considering the coronary heart disease equivalency of T2D among Iranian population, [4] in line with the Inter99 Study, [16] we decided not to miss more than $25 \%$ of at-risk participants and fixed the sensitivity of all the anthropometric cut-points at about 75\%; the cut-points resulted in specificities above $50 \%$ in all of the anthropometric measures except HC. Accordingly, for BMI, we recommend using $25.56 \mathrm{~kg} / \mathrm{m}^{2}$ as a predictive cut-point in men and $27.12 \mathrm{~kg} / \mathrm{m}^{2}$ in women. Data of the national non-communicable disease risk factors surveillance in Iran suggested cut-points close to the current study (24.8 $\mathrm{kg} / \mathrm{m}^{2}$ in men and $26.3 \mathrm{~kg} / \mathrm{m}^{2}$ in women) [56]. Assessing the accuracy of the ADA suggested cut-point [29] of $\mathrm{BMI} \geq 25 \mathrm{~kg} / \mathrm{m}^{2}$ in our population, its sensitivity and specificity were 89.2 and $37.5 \%$ in women and 78.8 and $46.7 \%$ in men, respectively which have noticeably lower specificities compared to our suggested cut-points. Our recommended cut-points for WC are $89 \mathrm{~cm}$ in men and $87 \mathrm{~cm}$ in women. Studies in different populations suggest different WC cut-points for predicting T2D which sounds reasonable due to ethnic differences [23, 24].
IDF suggested to use $W C \geq 94 \mathrm{~cm}$ and $\geq 80 \mathrm{~cm}$ in Middle-Eastern men and women, respectively [57]. Comparison between the false positive rates using our derived cut-points versus the ones suggested by IDF shows that our derived cut-point of $87 \mathrm{~cm}$ in women performed better ( 0.42 versus 0.66 , respectively), however, in men, IDF cut-points showed lower false positive rates (0.47 and 0.30 , respectively). But it should be considered that the sensitivity of WC cut-point suggested by IDF decreased to $54.2 \%$; the issue which is not appropriate for screening T2D [16]. As a general finding in our study, when fixing the sensitivity at $75 \%$, there was not a noticeable difference in specificity and PPV of the cut-points in men but in women, WHtR suggested cut-point had a higher specificity and PPV compared to other indices. Focusing on WHtR, we suggest the cut-point of 0.52 in men and 0.56 in women, results that somewhat support findings of a systematic review by Ashwell et al [13] to "keep your waist to less than half your height". However, our derived cut-points showed a lower false positive rate both in men (0.46 versus 0.58$)$ and women $(0.38$ versus 0.67$)$. 
Table 5 Joint-effects of BMI and other central obesity measures on the hazard of type 2 diabetes in women, TLGS study

\begin{tabular}{|c|c|c|c|c|c|c|c|}
\hline & \multirow{2}{*}{$\begin{array}{l}\text { Incident T2D /total participants } \\
\text { (\%) }\end{array}$} & \multicolumn{2}{|c|}{ Univariate model } & \multicolumn{2}{|l|}{ Model $1^{a}$} & \multicolumn{2}{|l|}{ Model $2^{b}$} \\
\hline & & HR (95\% Cl) & $P$ value & $\mathrm{HR}(95 \% \mathrm{Cl})$ & $P$-value & $\mathrm{HR}(95 \% \mathrm{Cl})$ & $P$-value \\
\hline \multicolumn{8}{|l|}{ BMI $\left(\mathrm{kg} / \mathrm{m}^{2}\right)-W C(\mathrm{~cm})$} \\
\hline$<27.12-<87$ & 77/1776(4.34) & Reference & - & Reference & - & Reference & - \\
\hline$\geq 27.12-<87$ & 44/389(11.31) & $2.29(1.58-3.33)$ & $<0.001$ & $1.89(1.29-2.75)$ & 0.001 & $1.79(1.22-2.61)$ & 0.003 \\
\hline$<27.12-\geq 87$ & 46/309(14.86) & $2.66(1.83-3.87)$ & $<0.001$ & $2.05(1.41-2.97)$ & $<0.001$ & $1.99(1.36-2.89)$ & $<0.001$ \\
\hline$\geq 27.12-\geq 87$ & $323 / 1555(20.77)$ & $3.76(2.89-4.89)$ & $<0.001$ & $2.30(1.75-3.02)$ & $<0.001$ & $2.06(1.53-2.77)$ & $<0.001$ \\
\hline \multicolumn{8}{|l|}{$\mathrm{BMI}\left(\mathrm{kg} / \mathrm{m}^{2}\right)-\mathrm{WH} \mathrm{tR}$} \\
\hline$<27.12-<0.56$ & 81/1848(4.38) & Reference & - & Reference & - & Reference & - \\
\hline$\geq 27.12-<0.56$ & 42/463(9.07) & $1.86(1.27-2.70)$ & 0.001 & $1.45(0.99-2.11)$ & 0.053 & $1.36(0.92-1.99)$ & 0.113 \\
\hline$<27.12-\geq 0.56$ & $42 / 237(17.72)$ & $3.13(2.13-4.60)$ & $<0.001$ & $2.33(1.59-3.43)$ & $<0.001$ & $2.32(1.58-3.42)$ & $<0.001$ \\
\hline$\geq 27.12-\geq 0.56$ & $325 / 1481(21.94)$ & $4.02(3.11-5.21)$ & $<0.001$ & $2.51(1.92-3.29)$ & $<0.001$ & $2.27(1.70-3.03)$ & $<0.001$ \\
\hline \multicolumn{8}{|l|}{ BMI $\left(\mathrm{kg} / \mathrm{m}^{2}\right)-W H R$} \\
\hline$<27.12-<0.83$ & 46/1464(3.14) & Reference & - & Reference & - & Reference & - \\
\hline$\geq 27.12-<0.83$ & 85/703(12.09) & $3.25(2.25-4.67)$ & $<0.001$ & $2.31(1.59-3.34)$ & $<0.001$ & $2.11(1.44-3.08)$ & $<0.001$ \\
\hline$<27.12-\geq 0.83$ & $77 / 621(12.40)$ & $3.32(2.29-4.81)$ & $<0.001$ & $2.55(1.75-3.71)$ & $<0.001$ & $2.54(1.75-3.70)$ & $<0.001$ \\
\hline$\geq 27.12-\geq 0.83$ & 282/1241(22.72) & $5.67(4.10-7.86)$ & $<0.001$ & $3.33(2.37-4.67)$ & $<0.001$ & $2.99(2.10-4.25)$ & $<0.001$ \\
\hline \multicolumn{8}{|l|}{ BMI (kg/m2)- HC } \\
\hline$<27.12-<103$ & $92 / 1627$ (5.65) & Reference & - & Reference & - & Reference & - \\
\hline$\geq 27.12-<103$ & $37 / 214$ (17.29) & $2.39(1.63-3.52)$ & $<0.001$ & $1.68(1.13-2.48)$ & 0.009 & $1.56(1.05-2.31)$ & 0.026 \\
\hline$<27.12-\geq 103$ & $31 / 458(6.77)$ & $1.09(0.72-1.64)$ & 0.669 & $1.07(0.71-1.61)$ & 0.721 & $1.02(0.67-1.53)$ & 0.923 \\
\hline$\geq 27.12-\geq 103$ & $330 / 1730$ (19.08) & $2.66(2.10-3.38)$ & $<0.001$ & $1.79(1.40-2.30)$ & $<0.001$ & $1.58(1.20-2.07)$ & 0.001 \\
\hline
\end{tabular}

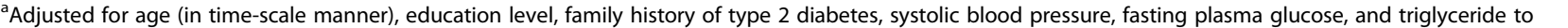
high-density lipoprotein cholesterol ratio

${ }^{\mathrm{b}}$ Adjusted for model 1 variables and wrist circumference

$H R$ hazard ratio, $C l$ confidence interval, $B M I$ body mass index, WC waist circumference, WHtR waist to height ratio, WHR waist to hip ratio, $H C$ hip circumference

Considering the limitation of the available data, $[19,20,58]$ the joint analyses in the current study extend the understanding of the combined influence of obesity measures on incident T2D. In line with our study, Meisinger et al. showed that there are

Table 6 Sex-specific Prediction Accuracy of the Combined High Anthropometric Indices for Incident Type 2 Diabetes, TLGS study

\begin{tabular}{|c|c|c|c|}
\hline & Sensitivity (\%) & Specificity (\%) & PPV (\%) \\
\hline \multicolumn{4}{|l|}{ Men $(\mathrm{N}=2419)$} \\
\hline $\mathrm{BMI} \geq 25.56-\mathrm{WC} \geq 89$ & $68.1 \%$ & $59.4 \%$ & $18.4 \%$ \\
\hline $\mathrm{BMI} \geq 25.56-\mathrm{WH} \mathrm{tR} \geq 0.52$ & $68.1 \%$ & $59.8 \%$ & $18.5 \%$ \\
\hline $\mathrm{BMI} \geq 25.56-\mathrm{WHR} \geq 0.91$ & $62.4 \%$ & $64.8 \%$ & $19.3 \%$ \\
\hline $\mathrm{BMI} \geq 25.56-\mathrm{HC} \geq 96$ & $68.4 \%$ & $58.2 \%$ & $18.0 \%$ \\
\hline \multicolumn{4}{|l|}{ Women ( $N=3319)$} \\
\hline $\mathrm{BMI} \geq 27.12-\mathrm{WC} \geq 87$ & $65.9 \%$ & $65.2 \%$ & $20.8 \%$ \\
\hline $\mathrm{BMI} \geq 27.12-\mathrm{WH} \mathrm{R} \geq 0.56$ & $66.3 \%$ & $67.3 \%$ & $21.9 \%$ \\
\hline $\mathrm{BMI} \geq 27.12-\mathrm{WHR} \geq 0.83$ & $57.6 \%$ & $72.9 \%$ & $22.7 \%$ \\
\hline $\mathrm{BMI} \geq 27.12-\mathrm{HC} \geq 103$ & $67.3 \%$ & $60.4 \%$ & $19.1 \%$ \\
\hline
\end{tabular}

$B M I$ body mass index, WC waist circumference, WHtR waist to height ratio, WHR waist to hip ratio, HC hip circumference, $P P V$ positive predictive value differences in the sex-specific relevance of measures of body fat distribution in predicting incident T2D [19]. In women, our findings suggested that different combinations of BMI-WC, BMI-WHtR, BMI-WHR, and BMI-HC (except high BMI-low WHtR and low BMI-high $\mathrm{HC}$ ) were associated with high risk of developing T2D. In men, we showed that high BMI either in conjunction with high obesity indices or normal ones (except for normal $\mathrm{HC}$ ) had a significant association with incidence of T2D in future, whereas those with normal BMI but high WHtR, WC or HC did not show a significant risk for the development of T2D. On the other hand, some studies proposed that BMI, WC, and WHR have very similar predictive powers for incident T2D $[19,20]$. This difference may be explained by variation in methodological approaches and the sample size. It should be kept in mind that although from a statistical point of view some of the anthropometric measures have a stronger association with T2D and can predict it better, from a clinical perspective we cannot say that one obesity measure overweighs the other. It would be rational to ask physicians to refer those with higher than normal 
obesity indices no matter which index is high. Furthermore, it seems that combined high values of general and central obesity indices increase the specificity for the price of reduced sensitivity and PPV in predicting incident T2D.

Considering limitations, our results cannot be extrapolated to elder populations since participants of our study are adults, 20-60 years of age. In addition, excluding participants affected by conditions such as autoimmune diseases and acute or chronic infections which are known to impair glucose tolerance was not possible at baseline examination; however, those suffering from cancer, end-stage renal disease or cirrhosis were excluded. Likewise, we could not collect data regarding the use of estroprogestins in our participants, nevertheless, use of other drugs that have the potential to affect glucose impairment was carefully observed. Also, as shown in Table 1, respondent participants in our study generally had significantly higher levels of risk factors which might lead to overestimation of T2D incidence. These statistically significant differences might be attributed to large study sample size and they are not significant from the clinical point of view (e.g. mean of $\mathrm{WHtR}=0.51$ and 0.50 in respondents and non-respondents men, respectively). Moreover, almost all of the risk factors were adjusted in the multivariable models. Finally, unfortunately, HbA1C was not measured in TLGS participants; hence, we could not use HbA1c as a criterion for defining diabetic patients.

As for the strengths, our study included a large representative sample of Iranian adults in a sex-stratified population with reliable follow-up data. We had a reasonable number of events which allowed us to evaluate the long-term effects of anthropometric indices on T2D incidence. Also, we used both FPG and 2 h-PCPG as indicators of diabetes status both at baseline and follow-up examinations allowing us to have an accurate estimation of incident T2D.

\section{Conclusions}

In conclusion, all anthropometric variables showed significant association with incident T2D considering a wide set of covariates including wrist circumferencein both sexes, except hip circumference in men. We showed that among all the obesity indices, in both sexes, WHtR performed the best while HC had the lowest prediction power. Fixing sensitivity at about $75 \%$, not to miss more than $25 \%$ of at-risk individuals for development of T2D in long term, our derived cut-points for BMI, WC, WHtR, WHR, and HC in the Iranian population were $25.56 \mathrm{~kg} / \mathrm{m}^{2}, 89 \mathrm{~cm}, 0.52,0.91$, and $96 \mathrm{~cm}$ in men and $27.12 \mathrm{~kg} / \mathrm{m}^{2}, 87 \mathrm{~cm}, 0.56,0.83$, and 103 in women, respectively. Our derived cut-points for BMI and WHtR in both sexes, and WC in women are higher than the traditionally used cut-points, leading to a considerable reduction in false positive rates. Therefore, they might perform better if applied in the Iranian population. Further studies in other Iranian populations are required to check the external validity of our proposed cut-points in predicting development of T2D.

\section{Additional files}

\begin{abstract}
Additional file 1: The selection process of study sample to determine optimal cut-points for prediction of type 2 diabetes. Figure legend: The hatched (those who were free of T2D in the last follow-up examination, despite not participating in one or more follow-ups) and grey (those who developed T2D in each of the follow-up examinations) boxes indicate study sample.T2D, type 2 diabetes mellitus; Lost, lost to follow-up. (PDF 2766 kb)

Additional file 2: Baseline Characteristics of Respondents and Nonrespondents, Tehran Lipid and Glucose Study (1999-2015). Table comparing baseline characteristics of respondents and non-respondents in the study. (DOCX $14 \mathrm{~kb}$ )
\end{abstract}

\section{Abbreviations}

2 h-PCPG: 2 h-post-challenge plasma glucose; 95\% Cls: 95\% confidence intervals; AUC: Area under the curve; BMI: Body mass index; DBP: Diastolic blood pressure; FPG: Fasting plasma glucose; HDL-C: High-density lipoprotein cholesterol; LMICs: Low- and middle-income countries; ROC: Receiver operating characteristics; SBP: Systolic blood pressure; SD: Standard deviation; T2D: Type 2 diabetes; TG: Triglycerides; TLGS: Tehran Lipid and Glucose Study; WC: Waist circumference; WHR: Waist to hip; WHtR: Waist to height ratios

\section{Acknowledgments}

We would like to acknowledge Ms. N Shiva of the Research Institute for Endocrine Sciences for critical editing of English grammar and syntax of the manuscript. This article has been extracted from the thesis written by Mrs. N Zafari in the School of Medicine, Shahid Beheshti University of Medical Sciences. (Registration No: 259).

\section{Funding}

This study was supported by Grant No.121 from the National Research Council of the Islamic Republic of Iran.

\section{Availability of data and materials}

The datasets used and/or analysed during the current study are available from the corresponding author on reasonable request.

\section{Authors' contributions}

$\mathrm{NZ}, \mathrm{FH}, \mathrm{FA}$, conceptualized the research question. NZ, ML, MAM, DK, FH, planned the methodological aspects.NZ, ML, MAM, DK, FH, PHM, conducted the statistical analysis.NZ, ML, wrote the original draft.NZ, ML, MAM, DK, FA, $\mathrm{FH}$, reviewed and edited the draft. MAM, DK, FA, FH, supervised the project. $\mathrm{DK}, \mathrm{FA}, \mathrm{FH}$, administered the project. FA, FH, acquired funding for the project. All authors read and approved the final manuscript.

Ethics approval and consent to participate

All subjects filled a written consent after being informed about the general aspects of the work and the study was approved by the Ethical Committee of Research Institute for Endocrine Sciences.

Competing interests

The authors declare that they have no competing interests.

\section{Publisher's Note}

Springer Nature remains neutral with regard to jurisdictional claims in published maps and institutional affiliations. 


\section{Author details}

'Prevention of Metabolic Disorders Research Center, Research Institute for Endocrine Sciences, Shahid Beheshti University of Medical Sciences, Tehran, Iran. ${ }^{2}$ Non-Communicable Disease Control, School of Population and Global Health, University of Melbourne, Melbourne, VIC, Australia. ${ }^{3}$ Department of Epidemiology and Biostatistics, School of Public Health, Tehran University of Medical Sciences, Tehran, Iran. ${ }^{4}$ Endocrine Research Center, Research Institute for Endocrine Sciences, Shahid Beheshti University of Medical Sciences, Tehran, Iran

\section{Received: 16 July 2017 Accepted: 25 May 2018} Published online: 05 June 2018

\section{References}

1. Murray C, Vos T, Lozano R, AlMazroa MA, Memish ZA: Disability-adjusted life years (DALYs) for 291 diseases and injuries in 21 regions, 1990-2010: a systematic analysis for the global burden of disease study 2010 (vol 380, pg 2197, 2012) Lancet 2013, 381(9867):628-628.

2. Haffner SM, Lehto S, Rönnemaa T, Pyörälä K, Laakso M. Mortality from coronary heart disease in subjects with type 2 diabetes and in nondiabetic subjects with and without prior myocardial infarction. N Engl J Med. 1998; 339(4):229-34.

3. Juutilainen A, Lehto S, Rönnemaa T, Pyörälä K, Laakso M. Type 2 diabetes as a "coronary heart disease equivalent" an 18-year prospective populationbased study in Finnish subjects. Diabetes Care. 2005;28(12):2901-7.

4. Hadaegh F, Fahimfar N, Khalili D, Sheikholeslami F, Azizi F. New and known type 2 diabetes as coronary heart disease equivalent: results from 7.6 year follow up in a Middle East population. Cardiovasc Diabetol. 2010;9(1):84.

5. IDF Diabetes Atlas. In. Brussels, Belgium: International Diabetes Federation: International Diabetes Federation; 2013.

6. Merlotti C, Morabito A, Ceriani V, Pontiroli AE. Prevention of type 2 diabetes in obese at-risk subjects: a systematic review and meta-analysis. Acta Diabetol. 2014:51(5):853-63.

7. Bell J, Kivimaki M, Hamer M. Metabolically healthy obesity and risk of incident type 2 diabetes: a meta-analysis of prospective cohort studies. Obes Rev. 2014;15(6):504-15.

8. Cameron AJ, Dunstan DW, Owen N, Zimmet PZ, Barr EL, Tonkin AM Magliano DJ, Murray SG, Wellborn TA, Shaw JE. Health and mortality consequences of abdominal obesity: evidence from the AusDiab study. Med J Aust. 2009;191(4):202-8.

9. Freemantle $\mathrm{N}$, Holmes J, Hockey A, Kumar S. How strong is the association between abdominal obesity and the incidence of type 2 diabetes? Int J Clin Pract. 2008;62(9):1391-6.

10. Derakhshan A, Sardarinia M, Khalili D, Momenan AA, Azizi F, Hadaegh F. Sex specific incidence rates of type 2 diabetes and its risk factors over 9 years of follow-up: Tehran Lipid and Glucose Study. PloS one. 2014;9(7):e102563.

11. Després J-P. Body fat distribution and risk of cardiovascular disease an update. Circulation. 2012;126(10):1301-13.

12. Kodama S, Horikawa C, Fujihara K, Heianza Y, Hirasawa R, Yachi Y, Sugawara A, Tanaka S, Shimano $H$, lida KT. Comparisons of the strength of associations with future type 2 diabetes risk among anthropometric obesity indicators, including waist-to-height ratio: a meta-analysis. Am J Epidemiol. 2012; 176(11):959-69.

13. Ashwell M, Gunn P, Gibson S. Waist-to-height ratio is a better screening too than waist circumference and BMI for adult cardiometabolic risk factors: systematic review and meta-analysis. Obes Rev. 2012;13(3):275-86.

14. Chei C-L, Iso H, Yamagishi $K$, Tanigawa T, Cui R, Imano H, Kiyama M, Kitamura A, Sato S, Shimamoto T. Body fat distribution and the risk of hypertension and diabetes among Japanese men and women. Hypertens Res. 2008;31(5):851.

15. Tulloch-Reid MK, Williams DE, Looker HC, Hanson RL, Knowler WC. Do measures of body fat distribution provide information on the risk of type 2 diabetes in addition to measures of general obesity? Comparison of anthropometric predictors of type 2 diabetes in pima Indians. Diabetes Care. 2003;26(9):2556-61.

16. Glümer C, Carstensen B, Sandbæk A, Lauritzen T, Jørgensen T, BorchJohnsen K. A Danish diabetes risk score for targeted screening the Inter99 study. Diabetes Care. 2004;27(3):727-33.

17. Wannamethee S, Papacosta O, Whincup P, Carson C, Thomas M, Lawlor D, Ebrahim S, Sattar N. Assessing prediction of diabetes in older adults using different adiposity measures: a 7 year prospective study in 6,923 older men and women. Diabetologia. 2010:53(5):890-8.

18. Huerta JM, Tormo M-J, Chirlaque M-D, Gavrila D, Amiano P, Arriola L, Ardanaz E, Rodríguez L, Sánchez M-J, Mendez M. Risk of type 2 diabetes according to traditional and emerging anthropometric indices in Spain, a Mediterranean country with high prevalence of obesity: results from a large-scale prospective cohort study. BMC Endocr Disord. 2013;13(1):7.

19. Meisinger $C$, Döring $A$, Thorand $B$, Heier M, Löwel H. Body fat distribution and risk of type 2 diabetes in the general population: are there differences between men and women? The MONICA/KORA Augsburg cohort study. Am J Clin Nutr. 2006:84(3):483-9.

20. Wang Y, Rimm EB, Stampfer MJ, Willett WC, Hu FB. Comparison of abdominal adiposity and overall obesity in predicting risk of type 2 diabetes among men. Am J Clin Nutr. 2005;81(3):555-63.

21. Jia Z, Zhou Y, Liu X, Wang Y, Zhao X, Wang Y, Liang W, Wu S. Comparison of different anthropometric measures as predictors of diabetes incidence in a Chinese population. Diabetes Res Clin Pract. 2011;92(2):265-71.

22. Xin Z, Liu C, Niu W-Y, Feng J-P, Zhao L, Ma Y-H, Hua L, Yang J-K. Identifying obesity indicators which best correlate with type 2 diabetes in a Chinese population. BMC Public Health. 2012;12(1):732

23. Razak F, Anand SS, Shannon H, Vuksan V, Davis B, Jacobs R, Teo KK, McQueen M, Yusuf S. Defining obesity cut points in a multiethnic population. Circulation. 2007;115(16):2111-8.

24. EC WHO. Appropriate body-mass index for Asian populations and its implications for policy and intervention strategies. Lancet. 2004;363(9403): 157.

25. Esteghamati A, Etemad K, Koohpayehzadeh J, Abbasi M, Meysamie A, Noshad S, Asgari F, Mousavizadeh M, Rafei A, Khajeh E. Trends in the prevalence of diabetes and impaired fasting glucose in association with obesity in Iran: 2005-2011. Diabetes Res Clin Pract. 2014;103(2):319-27.

26. Talaei M, Sadeghi M, Marshall T, Thomas G, Iranipour R, Nazarat N, Sarrafzadegan N. Anthropometric indices predicting incident type 2 diabetes in an Iranian population: the Isfahan cohort study. Diabetes \& metabolism. 2013:39(5):424-31.

27. Azizi F, Ghanbarian A, Momenan AA, Hadaegh F, Mirmiran P, Hedayati M, Mehrabi $Y$, Zahedi-Asl S. Prevention of non-communicable disease in a population in nutrition transition: Tehran lipid and glucose study phase II. Trials. 2009;10(1):5.

28. Azizi F, Madjid M, Rahmani M, Emami H, Mirmiran P, Hadjipour R. Tehran lipid and glucose study (TLGS): rationale and design. Iranian J Endocrinol and Metab. 2000;2(2):77-86.

29. Association AD. 2. Classification and diagnosis of diabetes. Diabetes Care. 2017:40(Supplement 1):S11-24.

30. Bozorgmanesh M, Hadaegh F, Saadat N, Azizi F. Fasting glucose cutoff point: where does the risk terminate? Tehran lipid and glucose study. Acta Diabetol. 2012;49(5):341-8

31. Pencina MJ, Larson MG, D'Agostino RB. Choice of time scale and its effect on significance of predictors in longitudinal studies. Stat Med. 2007:26(6):1343-59.

32. Jahangiri Noudeh $Y$, Hadaegh F, Vatankhah N, Momenan AA, Saadat N, Khalili D, Azizi F. Wrist circumference as a novel predictor of diabetes and prediabetes: results of cross-sectional and 8.8-year follow-up studies. J Clin Endocrinol Metab. 2013:98(2):777-84.

33. Verbeke $\mathrm{G}$. Linear mixed models for longitudinal data. In: Linear mixed models in practice: Springer; 1997. p. 63-153.

34. Cleves MA, Rock L. From the help desk: comparing areas under receiver operating characteristic curves from two or more probit or logit models. Stata J. 2002;2(3):301-13.

35. Lopez-Raton M, Rodrıguez-Alvarez MX, Cadarso-Suárez C, Gude-Sampedro F. OptimalCutpoints: an R package for selecting optimal Cutpoints in diagnostic tests. J Stat Softw. 2014;61(8):1-36.

36. Perkins NJ, Schisterman EF. The inconsistency of "optimal" cutpoints obtained using two criteria based on the receiver operating characteristic curve. Am J Epidemiol. 2006;163(7):670-5.

37. Vazquez G, Duval S, Jacobs DR, Silventoinen K. Comparison of body mass index, waist circumference, and waist/hip ratio in predicting incident diabetes: a meta-analysis. Epidemiol Rev. 2007;29(1):115-28.

38. Schulze MB, Heidemann C, Schienkiewitz A, Bergmann MM, Hoffmann K, Boeing $\mathrm{H}$. Comparison of anthropometric characteristics in predicting the incidence of type 2 diabetes in the EPIC-Potsdam study. Diabetes Care. 2006;29(8):1921-3. 
39. Borné Y, Nilsson PM, Melander O, Hedblad B, Engström G. Multiple anthropometric measures in relation to incidence of diabetes: a Swedish population-based cohort study. The European J Public Health. 2015:ckv044.

40. Wei M, Gaskill SP, Haffner SM, Stern MP. Waist circumference as the best predictor of noninsulin dependent diabetes mellitus (NIDDM) compared to body mass index, waist/hip ratio and other anthropometric measurements in Mexican Americans-a 7-year prospective study. Obes Res. 1997;5(1):16-23.

41. Parker ED, Pereira MA, Stevens J, Folsom AR. Association of hip circumference with incident diabetes and coronary heart disease: the atherosclerosis risk in communities study. Am J Epidemiol. 2009;169(7):837-47.

42. Conway B, Xiang Y-B, Villegas R, Zhang X, Li H, Wu X, Yang G, Gao Y-T, Zhang $W$, Shu X-O. Hip circumference and the risk of type 2 diabetes in middle-aged and elderly men and women: the shanghai women and shanghai men's health studies. Ann Epidemiol. 2011;21(5):358-66.

43. Janghorbani M, Amini M. Associations of hip circumference and height with incidence of type 2 diabetes: the Isfahan diabetes prevention study. Acta Diabetol. 2012;49(1):107-14.

44. Seidell JC, Pérusse L, Després J-P, Bouchard C. Waist and hip circumferences have independent and opposite effects on cardiovascular disease risk factors: the Quebec family study. Am J Clin Nutr. 2001;74(3):315-21.

45. Snijder MB, Dekker JM, Visser M, Yudkin JS, Stehouwer CD, Bouter LM, Heine RJ, Nijpels G, Seidell JC. Larger thigh and hip circumferences are associated with better glucose tolerance: the Hoorn study. Obesity. 2003;11(1):104-11.

46. Chan M: Obesity and Diabetes: the Slow-motion Disaster Keynote Address at the 47th Meeting of the National Academy of Medicine In.; 2016

47. Snijder MB, Dekker JM, Visser M, Bouter LM, Stehouwer CD, Yudkin JS, Heine RJ, Nijpels G, Seidell JC. Trunk fat and leg fat have independent and opposite associations with fasting and postload glucose levels: the Hoorn study. Diabetes Care. 2004;27(2):372-7.

48. Janghorbani M, Momeni F, Dehghani M. Hip circumference, height and risk of type 2 diabetes: systematic review and meta-analysis. Obes Rev. 2012;13(12):1172-81

49. Cameron A, Magliano D, Söderberg S. A systematic review of the impact of including both waist and hip circumference in risk models for cardiovascular diseases, diabetes and mortality. Obes Rev. 2013;14(1):86-94.

50. Seidell J, Han T, Feskens EJ, Lean M. Narrow hips and broad waist circumferences independently contribute to increased risk of non-insulindependent diabetes mellitus. J Intern Med. 1997;242(5):401-6.

51. Arner P. Differences in lipolysis between human subcutaneous and omental adipose tissues. Ann Med. 1995;27(4):435-8.

52. Manolopoulos K, Karpe F, Frayn K. Gluteofemoral body fat as a determinant of metabolic health. Int J Obes. 2010;34(6):949.

53. Kuk JL, Janiszewski PM, Ross R. Body mass index and hip and thigh circumferences are negatively associated with visceral adipose tissue after control for waist circumference. Am J Clin Nutr. 2007;85(6):1540-4.

54. Hadaegh F, Shafiee G, Azizi F. Anthropometric predictors of incident type 2 diabetes mellitus in Iranian women. Annals of Saudi medicine. 2009;29(3):194.

55. Hadaegh F, Zabetian A, Harati H, Azizi F. Waist/height ratio as a better predictor of type 2 diabetes compared to body mass index in Tehranian adult men-a 3.6-year prospective study. 2006;1 14(6):310-5.

56. Shabnam A-A, Homa K, Reza M, Bagher L, Hossein FM, Hamidreza A. Cut-off points of waist circumference and body mass index for detecting diabetes, hypercholesterolemia and hypertension according to National nonCommunicable Disease Risk Factors Surveillance in Iran. Arch Med Sci. 2012;8(4):614-21.

57. Alberti K, Eckel RH, Grundy SM, Zimmet PZ, Cleeman Jl, Donato KA, Fruchart J-C, James WPT, Loria CM, Smith SC. Harmonizing the metabolic syndrome: a joint interim statement of the international diabetes federation task force on epidemiology and prevention; national heart, lung, and blood institute; American heart association; world heart federation; international atherosclerosis society; and international association for the study of obesity. Circulation. 2009;120(16):1640-5.

58. Folsom AR, Kushi LH, Anderson KE, Mink PJ, Olson JE, Hong C-P, Sellers TA, Lazovich D, Prineas RJ. Associations of general and abdominal obesity with multiple health outcomes in older women: the lowa Women's health study. Arch Intern Med. 2000;160(14):2117-28.

\section{Ready to submit your research? Choose BMC and benefit from:}

- fast, convenient online submission

- thorough peer review by experienced researchers in your field

- rapid publication on acceptance

- support for research data, including large and complex data types

- gold Open Access which fosters wider collaboration and increased citations

- maximum visibility for your research: over $100 \mathrm{M}$ website views per year

At BMC, research is always in progress.

Learn more biomedcentral.com/submissions 